\title{
Record
}

\section{Sir Robert Watson-Watt, Kt., c.B., LL.D., D.sc.,}

\author{
F.R.S.
}

A CONFERENCE on Radar-Present and Future held in London last October was attended by 600 delegates from 22 countries. In the opening address it was said that our present knowledge covered 90 per cent of the technical aspects of the subject. The 68 papers discussed in the following three days showed the extent of the remaining tenth.

This whole field of applied science can be traced to a few scientists working largely in isolation in different countries before World War II. As with many advances in scientific development the subject was 'in the air' and those sensitive to it had genuinely independent approaches and some partial solutions. But Robert Watson-Watt, who died at the age of eighty-one on 5 December 1973, can be uniquely identified as having conceived and carried into successful application the first operational systems.

The profound effect of radar on the course of the war tends to mask the other contributions he made to the understanding and use of radio on a wide front. From the time he joined the Meteorological Office in 1915 and investigated the location of thunderstorms at great distances he was always concerned with the frontiers of his subject. These included the behaviour of the conducting regions of the upper atmosphere-for which regions he coined the name ionosphere in 1932 -studies of communication systems for the Royal Air Force which were the origins of operational research, and the invention of the cathode ray directionfinder.

The instantaneous display of direction on a cathode ray tube gave a new strength to the oldest radio aid to navigation, both in the long-wave version for meteorology and in the high frequency system which became the pointer for the Fleet in the battle of the Atlantic.

There is a further reason to be grateful to Watson-Watt in his support for the Royal Institute of Navigation in its formative years. He attended the inaugural meeting in March 1947 and was elected a Vice-President at the first Annual General Meeting. In 1949 he was elected President and served in this capacity for two years. He had a gift for clarity of exposition and a wide view of political and social problems which made his public addresses stimulating and never narrowly technical.

He was knighted in 1942, became a Fellow of the Royal Society, and was awarded $£_{50}, 000$ by the Royal Commission on Awards to Inventors. It could be said that his great ability was matched by his good fortune in being concerned with a fast-moving and dramatically rewarding field of technology, and also in the adequate and not too tardy public recognition of his achievements. But it is also difficult to express how great a debt is owed to him for the consequences of his work. The Royal Institute of Navigation has particular cause to record a deep appreciation for the life and work of one of the leading scientists of our time.

G. E. Beck 